\title{
Interviewing to Understand Strengths
}

\author{
Michael R. Hass ${ }^{a, *}$
}

\author{
Received: 15 September 2017 \\ Revised: $\quad 22$ October 2017 \\ Accepted: 29 November 2017 \\ ISSN: 1307-9298 \\ Copyright (C) IEJEE \\ www.iejee.com
}

DOI: 10.26822/iejee.2018336189

\begin{abstract}
Interviewing clients about their strengths is an important part of developing a complete understanding of their lives and has several advantages over simply focusing on problems and pathology. Prerequisites for skillfully interviewing for strengths include the communication skills that emerge from a stance of not knowing, developing a vocabulary of strengths that allows practitioners to identify and name them, and having a "ear for strengths." Building on this, Saleebey (2008) offers a framework of eight types of questions that allow us to explore strengths in depth with clients.
\end{abstract}

Keywords: Interviewing, strengths perspective, counseling

\section{Introduction}

Mental health professionals have long embraced interviewing as an important way of gathering information. There is a long history of the use of interviewing in making diagnostic decisions and better understanding client problems. More recently, greater attention has been placed on giving client strengths and resources "equal space, equal time, equal emphasis" (Lopez, Snyder \& Rasmussen; 2003, p. 17) as problems and psychopathology in the interviewing process.

Including strengths is important for several reasons. One is that when adults recognize children and youths' strengths, they are more likely to actively take part in the assessment process and later treatment (Epstein, Hertzog, \& Reid, 2001; Murphy, 2015 Nickerson \& Fishman, 2013). Gathering information about strengths also broadens the focus of assessment to include recognizing and building competence rather than only reducing problem behaviors (Nickerson, 2007; Epstein et al., 2001). This is important because although reducing the negative impact of problems is important, evidence suggests that the presence of personal and social competence in children is a better predictor of functioning later in adulthood than the reduction of symptoms alone (Kohlberg, Ricks, \& Snarey, 1972; 1984). Given this, there is a strong argument to include assessing and building strengths as part of the counseling process.

Interviewing for strengths is the mirror image of interviewing children about their problems. When interviewing for strengths, counselors make use of the same communication skills important in clinical interviewing or in psychotherapy or counseling. These include the communication skills that emerge from what has been described as a stance of not knowing (Anderson \& Goolishian, 1992). Anderson and Goolishian (1992) describe not knowing as "...a general attitude or stance in which the therapist's actions communicate an abundant, genuine curiosity" (p. 29). Skills that communicate this curiosity exist on a continuum from relatively passive skills such as nonverbal attending to more active strategies like paraphrasing and accurately reflecting feelings (See Table 1 below).

Table 1. Skills for Not Knowing

Less active >>>>>>>>>>>>>>>>>>>>>>>More active

\begin{tabular}{lll}
\hline $\begin{array}{l}\text { Nonverbal } \\
\text { attending }\end{array}$ & $\begin{array}{l}\text { Minimal } \\
\text { encouragers }\end{array}$ & $\begin{array}{l}\text { Echoing } \\
\text { Paraphrasing \& } \\
\text { Summarizing }\end{array}$ \\
Observing & $\bullet$ Nodding & Complimenting \\
Waiting & $\begin{array}{l}\text { Ummm, okay, } \\
\text { sure, yes, wow! }\end{array}$ & Normalizing \\
& & \\
& & \\
& &
\end{tabular}

In addition to these basic skills, interviewing for strengths also requires a vocabulary of strengths. Although there is no Diagnostic and Statistical Manual (APA 2013) or International Classification of Disease (WHO, 1993) for

\footnotetext{
* Correspondence details: Michael R. Hass, Chapman University, Donna Ford Atallah College of Educational Studies. One University Drive, Orange, CA 92866. Phone 714-628-7217 E-Mail: mhass@chapman.edu
} 
strengths, there is abundant literature that offer at least a tentative map of strengths. One source is positive psychology (Seligman, 2004). Counselors and researchers in positive psychology have developed assessments and interventions that focus on increasing subjective wellbeing or happiness by promoting the experience of positive emotions (Fredrickson, 2001) or enhancing qualities such as gratitude (Emmons \& Stern, 2013), hope (Pedrotti, Edwards, \& Lopez, 2008) or optimism (Gillham, Reivich, \& Shatté, 2001).

A second important contribution to a map of strengths is resilience (Masten, 2014). Research on resilience grew out of research with children whose parents had serious mental illnesses (Luthar, Cicchetti, \& Becker, 2000). The finding that many of these children did well in life despite the challenges they faced led researchers to a set of social and psychological factors that seemed to promote positive outcomes among children who had faced adversities such as poverty or abuse (e.g., Garmezy, 1993; Masten \& Curtis, 2000; Rutter, 2013). Researchers found that although it was true that children exposed to these adversities often have more psychosocial problems than those who were not exposed, the large majority still grew up to lead productive adult lives (e.g., Benard, 2004; Werner \& Smith, 2001; Cicchetti, Rogosch, Lynch, \& Holt, 1993).

Masten (2014) has argued there are basic psychosocial systems that, when functioning well, are universally protective of human development and form the core of resilience. These dynamic adaptive systems include: 1) attachment and close relationships; 2) intelligence, ingenuity, and problem solving; 3) self-regulation and selfdirection; 4) mastery motivation and sense of personal agency; and 5) faith, hope and belief that life has meaning (pp.147-164). Using similar language, Benard (2004) proposes two broad categories of resilience: personal strengths, and environmental protective factors. Personal strengths include: 1) social competence, 2) problem solving, 3) autonomy, and 4) sense of purpose. Environmental protective factors can be found in families, communities, or schools and include: 1) caring relationships; 2) clear and positive expectations by family members, educators, and community members for achievement; and 3) opportunities to take part, contribute and give back (Benard, 2004).

If strengths are to be taken seriously, they must be systematically recognized and named. Although we do not have a DSM or ICD for strenghts, positive psychology and research on resilience offer a guide for what to look for when interviewing for strengths. These can be summarized as:

1. The quality of relationships with peers and family

2. The presence of cognitive or academic competencies

3. The presence of aspirations, goals, and plans

4. The sense that despite adversity, there is a purpose to life
5. A sense of agency or confidence in the ability to affect life and meet one's goals

\section{Developing an Ear for Strengths}

A prerequisite for assessing client strengths is to adopt the assumption that every student, family, or community has resources and capacities (Saleebey, 2008). We listen for and pay attention to what we believe is important in an assessment. If we assume that strengths are present, even if they are not easy to identify because they are obscured by problems, we become more curious about what might be beyond the presenting difficulties and investigate how client strengths contribute to their lives and how they can be used to improve their circumstances.

In addition to a strengths perspective, we must also have tools that can be used to unpack and better understand strengths once we have become curious about them. Saleebey (2008) discusses eight kinds of questions that help name and elaborate on strengths. These include : 1) perspective questions, 2) change questions, 3) meaning questions, 4) survival questions, 5) support questions, 6) possibility questions, 7) exception questions, and 8) esteem questions (p. 73).

\section{Perspective questions}

When counselors are curious about children's perspectives, they encourage autonomy and competence by signaling that what they themselves think or feel about their situations is important. This insider perspective is also critical in interviewing because it adds information about how different stakeholders (e.g., parents, teachers, students) view a situation and what they view as important. The insider perspective not only offers ecological validity for information from other sources such as school records, tests, or questionnaires, but it also facilitates a collaborative working relationship. Respect for the insider perspective offers a counterbalance to the expert knowledge that counselors bring to a situation.

Perspective question such as the ones below offer a useful starting place for a discussion of strengths:

- "What are your thoughts about how you got to this point?"

- "What have you been successful at so far?"

- "How did you make those successes happen?"

\section{Change questions}

Change questions are an extension of perspective questions. As part of the strengths perspective, we also assume that our clients, no matter how young or disturbed, are always trying to cope with their challenges even if they appear to have been unsuccessful so far. Rooted in these efforts are clients' theories of change (Duncan \& Miller, 2000). The assumption that clients have been working on their problems in some way long before we interview them leads us to be curious about what they have done so far and, more importantly, what they have done that worked, if only in small ways (De Jong \& Kim 
Berg, 2013; Duncan \& Miller, 2000). These questions might include:

- "What have you done to try to make things better? Have those things worked, even a little bit?"

- "What do you think might make things better?"

- "Lots of time, kids have good ideas about how to solve a problem. What do you think would help?"

\section{Meaning questions}

Meaning questions are also an extension of perspective questions. They try to get at what values, beliefs, or goals clients find important. Some of these are of course cultural and involve values or beliefs that the person views as shared by members of a particular community. These might include respect for elders, expectations for gender roles, the role of education in success in life, etc. Other beliefs arise from unique personal experiences that lead to what cognitive behavioral therapists refer to as core beliefs (Creed, Resiweber \& Beck, 2011). Creed et al. describe core beliefs as the foundation for how we view ourselves, relate to others and experience the world (2011). These values and beliefs can be both adaptive or limiting, depending on the context. In an investigation of strengths, the focus is on beliefs that are or could be a source of resilience. Meaning questions include:

- "What are the most important things about school for you?"

- "Where do you see yourself in five years?"

- "What do you think is most important in life?"

\section{Survival questions}

Survival questions are also known as coping questions (De Jong \& Kim Berg, 2013). They refocus attention away from feeling overwhelmed in the face of seemingly insurmountable challenges toward clients' efforts at coping with these adversities. Again, a strengths perspective leads counselors to assume that clients are always coping in one way or another, even it is just to be passive or withdrawn in the face of adversity. Survival questions are windows into potential strengths and resilience. It is important to understand that although these efforts at coping may not seem completely successful, they may have been helpful in small ways that can be built upon in developing plans and interventions.

When asking survival questions, it is important to first acknowledge that things have been difficult, even overwhelming. These acknowledgements serve to normalize clients' experiences and communicate that their thoughts and feelings are unsurprising given the circumstances they face.

The simplest way of starting a conversation about survival or coping is to ask, "What has helped so far?" (De Jong \& Kim Berg, 2013). Other questions include:

- "That sounds really tough. How have you managed to deal with all that?"
- "Wow, I am amazed you even got out of bed today and made it to school. How did you manage that?"

- "Given all that is going on, I am not surprised you feel overwhelmed. I wonder if anything has helped, even if only a little bit?"

\section{Support questions}

An important way in which clients cope is to access social support. The importance of social support is one of the most consistent findings in research on resilience (e.g., Masten, 2014; Benard, 2004; Werner \& Smith, 2001). Seeking social support begins early in development with attachment to a parent or caregiver and expands as children grow older to include adults and peers in schools, neighborhoods, and community institutions (Masten, 2014). Support questions include:

- "What are your friends like (ages, gender)? What are some things you like to do together?"

- "Who are you closest to in your family? How are you close?"

- "Who in your life helps you reach your goals or explore your interests?"

- "Name some people that you respect or that you see doing things you like or appreciate. What kinds of things do they do?"

- Do you belong to any clubs, teams, community organizations, or churches (synagogues, temples, etc.)?

- "What family, friends, professionals, institutions, organizations etc. have supported you? How? Are they still around? Do they still help?"

Another aspect of social connectedness is the notion of required helpfulness (Rachman, 1979). In many families, children assume the responsibility for caring for younger siblings, elderly grandparents, or ill parents (Werner \& Smith, 1992). These social responsibilities can of course be stressful, but they can also build confidence and a feeling of competence in children or adolescents. Interview questions that focus on required helpfulness include:

- "Who counts on you? What do you do for them?"

- "Tell me about a time you did something nice for someone else, or how you helped them out." "What types of things do you enjoy doing for others?"

- "How do you help out around the house?"

\section{Possibility questions}

It is difficult to underestimate the power of dreams, aspirations, and goals. As the astrophysicist and philosopher Erich Jantsch put it, "Mental anticipation now pulls the future into the present and reverses the direction of causality" (1980, p. 14). All the children and adolescents we work with are facing adversity of one kind or another. It is important for practitioners to remember 
that the children and adolescents we work with can be pulled into the future by a vision of themselves that goes beyond their current difficulties. Possibility questions clarify these dreams and aspirations, making them more vivid and possible. Possibility questions include the Miracle Question used by practitioners of Solution-Focused Brief Therapy (De Jong \& Kim Berg, 2013). Other possibility questions include:

- "So, if we could figure out a way to solve this problem, how would things be better?"

- "If things went well for you, where would you be in a year?"

- "What do want to get out of school?"

- "What do you dream about doing with your life?"

\section{Exception questions}

Exceptions are experiences when a problem might have happened but did not (De Shazer, 1988). Like survival questions, exceptions are windows into potential strengths. Counselors of Solution-Focused Brief Therapy (De Jong \& Kim Berg, 2013) use the acronym EARS to frame the process of interviewing for exceptions. E stands for elicit. Eliciting exceptions starts with learning to listen for and recognize exceptions. Exceptions can be found in school documents or records (Murphy, 2015), e.g., evidence of past good grades, or of doing better in certain classes even when not doing well in others. Eliciting exceptions can also be as straightforward as simply asking, "Has there been a time recently when things were better for you?" Other exceptions-eliciting questions include:

- "When does it seem that Mrs. Jones is not on your back as much?"

- "When is this less of a problem?"

- "So, what things about school do you want to keep the way they are?"

The $\mathbf{A}$ in EARS stands for amplify (De Jong \& Kim Berg, 2013). Amplifying exceptions involves gathering details about how the exceptions happened and what role the client played in making them happen. Murphy (2015) points out that the details of exceptions should be pursued with the same energy that practitioners often use to gather details about clients' problems.

The $\mathbf{R}$ in EARS stands for reinforce (Murphy, 2015). Reinforcing exceptions can be simply celebrating successes or what Kral and Kowalski (1989) call cheerleading. Cheerleading is a form of social reinforcement and can consist of simple statements such as:

$$
\begin{aligned}
& \text { - } \quad \text { "Way to go!" } \\
& \text { - "That's great!" } \\
& \text { - "Wow! That's fantastic!" }
\end{aligned}
$$

Another aspect of reinforcing exceptions that can be combined with cheerleading is positive blaming (Kral \& Kowalski, 1989) or giving credit (Murphy, 2015). Clients do not necessarily assume responsibility for what goes well and will often assume that when an exception takes place, it is a lucky accident and not the result of their own actions. Positive blaming extends social reinforcement and helps clients make connections between their thoughts and behaviors, and exceptions. For example, if a client shares an exception, follow-up questions might be:

- "Great, how did you figure out such a good idea?"

- "That's great...so, what did you do to make it easier for that to happen?"

- "That is great that you were able to do that...what does it say about you that you were able to come up with such a good idea?"

\section{Esteem questions}

Esteem questions are questions that investigate what someone does well, appreciates about themselves or feels competent doing. They can be as straightforward as:

- "When classes do you like best?"

- "What do you like to do in your free time?"

- "When do you feel really good about yourself?"

- "What do you enjoy most?

Another type of question that can be helpful in exploring what someone does well are relationship questions. Relationship questions allow the interviewer to access what clients think other people think about them. It also allows them to name strengths or preferred activities without the social pressure of directly owning that quality or activity. Examples include:

- "What do people like about you?"

- "What would your friends say you were good at?"

- "So, if your dad were here, what would he say that you did well around the house?"

\section{What Does a Conversation About Strengths Look Like?}

Counselors' work with children often starts with an assessment of what works and does not work in the lives of the clients we work with (Lopez, Snyder \& Rasmussen, 2003). Traditionally, counselors have focused more on what does not work than what works. If counselors are to achieve a holistic understanding of the clients they work with, it is important to develop a balance of understanding both what troubles our clients and what, despite these troubles, seems to be going well. This can be more difficult than it appears conceptually because counselors are often swimming upstream against their training and the pervasive bias toward the negative (e.g., problems, psychopathology, etc.). Below, the conversation between a counselor and lan, a 16-year-old junior in high school illustrates how the questions we have discussed above may look like in an actual interview. lan's teachers referred him because recently he is finishing less of his work and he seems more withdrawn. 
Currently, he has a diagnosis of Attention Deficit Hyperactivity Disorder (ADHD).

Counselor: "Hello Ian, I think I have seen you around school. Do you remember me?"

lan: "Yeah, you're the counselor, right?"

Counselor: "Yeah, that was me. Your history teacher said they are worried you're doing less work and seem more withdrawn."

Ian: "I don't know...I guess I'm not doing as much work."

Counselor: "Well, before we get into all that can I ask you some other questions?"

Ian: "Sure, go ahead."

Counselor: "Okay, to start, what classes do you like best?" [esteem question]

Ian: "I guess math and history."

Counselor: "Okay, what do you like about them?" [asking for detail]

Ian: "I am pretty good at math and I like the story part of history. You know...learning about how people lived and what happens to them."

Counselor: "Great, so, you do pretty well in those classes, then?"

Ian: "Yeah, I am still doing okay in those classes. Better than the others."

Counselor: "How about when you aren't in school. What do you enjoy doing then?" [esteem question]

Ian: "I like to play the guitar and play video games, but my mom won't let me play them too much at home"

Counselor: "So, what is the most important thing about school for you?" [meaning question]

Ian: "I know I need to go to university to get a good job. I don't want to end up like my dad. He's in jail, you know."

Counselor: “No, I didn't know that. So, getting a good job is important to you and you think that going to university is the best way to do that. What kind of a good job do you think you might want?"

lan: “I don't know for sure but maybe something in tech; I like to fix things and figure out how stuff goes together."

Counselor: "That's great....back to the thing with your teachers, what do you think is going on?" [perspective question]

Ian: “I don't know...I just don't feel it anymore. Like I just want to space out and do nothing."

Counselor: "Oh, okay. What do you think is going on with feeling like you just want to space out?"
Ian: "Not sure...there is so much going on. My mom keeps talking about how I need to get ready for when I graduate but that scares me, a lot."

Counselor: "I am not surprised you feel scared. Given all that is going on...has anything you've done helped, even if only a little bit?" [normalizing statement and survival question]

Ian: "[frowns] ...my history teacher is nice. She said she had to leave her house because her dad was really strange. I like listening to her talk about all that."

Counselor: "[smiles and nods] ....sounds like she is a good support for you. Who else is helpful?" [support question]

Ian: "I like my older sister...she is pretty easy to talk with."

Counselor: "That's good...I wonder what do you think might make things better for you?" [change question]

Ian: “Don't know...get more work done."

Counselor: "Okay, so if were able to do that, where would you be in a year?" [Possibility question]

lan: "I would be about to graduate...how crazy...maybe I would have a university picked out."

Counselor: "Great Ian...so, let me see if get this all straight. You are pretty good at math and history. You like to play the guitar and you are close to your history teacher. Also, you want to go to university and for sure don't want to end up like your dad. I just want to say that you have a lot going for you. [summary of strengths and amplification] Going back to the not being motivated and getting enough, what was different when that was better?" [elicit exception question]

lan: "I guess I wasn't thinking so much about what happens after high school. It freaks me out."

Counselor: "What do think would help not think about it so much? I guess you could distract yourself or sometimes I heard that when you make a plan about something it leads you not to worry so much."

Ian: "A plan...just thinking about it makes me feel weird."

Counselor: "I wonder if you might start by talking to your history teacher. She must have done something when she left home."

Ian: "Yeah, I am okay talking with her."

Counselor: "That is great. Before we stop, I have one more question. On a scale of one to ten, ten is you are totally freaked out and one is you are completely calm, where are you today?"

Ian: "I was an 8 when we started but maybe a 6 now." 
Counselor: "Okay, that's great. So, let's see where you are after talking to your history teacher. Let's talk in a few days, okay?"

Ian: "Sure."

It is important to notice that the counselor spent little time in this short session exploring lan's symptoms. Given what lan shared, it is significant to note that lan's loss of motivation in the face of his future could be a sign of depression. It would also be important to note that lan's ADHD may make it more difficult for him to make a systematic plan. These are important, but it is equally important to know that lan has aspirations, goals, and positive connections with adults and family members. Interviewing for strengths not only allowed the counselor and Ian to arrive at a potentially helpful plan without a great deal of focus on his problems, but also seemed to reduce lan's anxiety during the session. The skills for not knowing demonstrated in this dialogue also facilitated a collaborative relationship, making it more likely that if the time comes to discuss depression or ADHD, this conversation will be easier and potentially more productive.

\section{References}

American Psychiatric Association. (2013). Diagnostic and statistical manual of mental disorders (5th ed.). Washington, DC: Author.

Anderson, H., \& Goolishian, H. (1992). The client is the expert: A not-knowing approach to therapy. In. S. McNamee \& K. Gergen (Eds.), Social construction and the therapeutic process (pp. 25-39). Newbury Park, CA: Sage.

Benard, B. (2004). Resiliency: What we have learned. San Francisco, CA: WestEd

Cicchetti, D., Rogosch, F. A., Lynch, M., \& Holt, K. D. (1993). Resilience in maltreated children: Processes leading to adaptive outcome. Development \& Psychopathology, 5(4), 629. doi:10.1017/S0954579400006209

Creed, T. A., Reisweber, J., \& Beck, A. T. (2011). Cognitive therapy for adolescents in school settings. New York, NY, US: Guilford Press.

De Jong, P., \& Kim Berg, I. (2013). Interviewing for solutions. Belmont, Calif.: Brooks/Cole, Cengage Learning.

De Shazer, S. (1988). Clues: investigating solutions in brief therapy. New York: W.W. Norton, 3-17. doi:10.1177/0533316412474924

Duncan, B. L., \& Miller, S. D. (2000). The client's theory of change: Consulting the client in the integrative process. Journal of Psychotherapy Integration, 10(2), 169-187. doi:10.1023/A:1009448200244

Emmons, R. A., \& Stern, R. (2013). Gratitude as a psychotherapeutic intervention. Journal of Clinical Psychology, (8), 846. doi:10.1002/jclp.22020

Epstein, M. H., Hertzog, M. A., \& Reid, R. (2001). The Behavioral and Emotional Rating Scale: Long Term Test-Retest Reliability. Behavioral Disorders, (4). 314.
Fredrickson, B. L. (2001). The role of positive emotions in positive psychology: The broaden-and-build theory of positive emotions. The American Psychologist, 56(3), 218-226.

Garmezy, N. (1993). Children in poverty: Resilience despite risk. Psychiatry, 56, 127-136.

Gillham, J. E., Reivich, K. J., \& Shatté, A. J. (2001). Building optimism and preventing depressive symptoms in children. In E. C. Chang, E. C. Chang (Eds.), Optimism \& pessimism: Implications for theory, research, and practice (pp. 301-320). Washington, DC, US: American Psychological Association. doi:10.1037/10385-014

Jantsch, E. (1980). The self-organizing universe: scientific and human implications of the emerging paradigm of evolution. Oxford, U.K.: Pergamon Press.

Kohlberg, L., \& Ricks, D., \& Snarey, J. (1972). The predictability of adult mental health from childhood behavior. In B. B. Wolman (Ed.), Manual of child psychopathology (pp. 1217-1284). New York, NY: McGraw-Hill.

Kohlberg, L., \& Ricks, D., \& Snarey, J. (1984). Childhood development as a predictor of adaptation in adulthood. Genetic Psychology Monographs, 110, 91 172.

Kral, R., \& Kowalski, K. (1989). After the miracle: The second stage in solution focused brief therapy. Journal of Strategic \& Systemic Therapies, 8(2-3), 73-76.

Lopez, S. J., Snyder, C. R., \& Rasmussen, H. N. (2003). Striking a vital balance: Developing a complementary focus on human weakness and strength through positive psychological assessment. In S. J. Lopez \& C. R. Snyder (Eds.). Positive psychological assessment: A handbook of models and measures. Washington, DC: American Psychological Association.

Luthar, S. S., Cicchetti, D., \& Becker, B. (2000). The construct of resilience: a critical evaluation and guidelines for future work. Child Development, 71(3), 543-562.

Masten, A. S. (2014). Ordinary magic: Resilience in development. New York, NY, US: Guilford Press.

Masten, A. S., \& Curtis, W. J. (2000). Integrating competence and psychopathology: Pathways toward a comprehensive science of adaption in development. Development and Psychopathology, 12(3), 529-550. doi:10.1017/S095457940000314X

Murphy, J. J. (2015). Solution-focused counseling in schools., 3rd ed. Alexandria, VA, US: American Counseling Association.

Nickerson, A. B. (2007). The use and importance of strength-based assessment. School Psychology Forum: Research in Practice, 2, 15-25. f

Nickerson, A. B., \& Fishman, C. E. (2013). Promoting mental health and resilience through strength-based assessment in US schools. Educational and Child Psychology, 30(4), 7-1. 
Pedrotti, J. T., Edwards, L. M., \& Lopez, S. J. (2008). Promoting Hope: Suggestions for School Counselors. Professional School Counseling, 12(2), 100-107.

Rachman, S. (1979). The concept of required helpfulness. Behaviour Research and Therapy, 17(1), 1-6. doi:10.1016/0005-7967(79)90044-5

Rutter, M. (2013). Annual research review: ResilienceClinical implications. Journal Of Child Psychology And Psychiatry, 54(4), 474-487. doi:10.1111/j.14697610.2012.02615.x

Saleebey, D. (2008). Commentary on the Strengths Perspective and Potential Applications in School Counseling. Professional School Counseling, 12(2), 6875.

Seligman, M. P. (2004). Authentic happiness: using the new positive psychology to realize your potential for lasting fulfillment. New York: Free Press, 2004.

Werner, E. E., \& Smith, R. S. (1992). Overcoming the odds: High risk children from birth to adulthood. Ithaca, NY: Cornell University Press.

Werner, E. E., \& Smith, R. S. (2001). Journeys from childhood to midlife: Risk, resilience, and recovery. Ithaca, NY, US: Cornell University.

World Health Organization. (1993). ICD-10, the ICD-10 classification of mental and behavioural disorders: Diagnostic criteria for research. Geneva: World Health Organization. 
This page is intentionally left blank

www.iejee.com 